\title{
Bacteriophage Growth Promoters in Poultry
}

\section{Bacteriófagos como Sustituto de Promotores de Crecimiento Tipo Antibiótico en Avicultura}

\section{Honorio Javes and Y. Vallenas Sánchez}

Dpto. de Alimentación animal Facultad de Medicina Veterinaria y Zootecnia de la Universidad Privada Antenor Orrego, Trujillo, Peru

\section{Abstract}

I International Seminar of Livestock and Agroindustrial Production ESPOCH 2020

Corresponding Author:

Y. Vallenas Sánchez

yvallenass1@upao.edu.pe

Published: 2 September 2021

Production and Hosting by

Knowledge E

(c) C. Honorio Javes and $Y$. Vallenas Sánchez. This article is distributed under the terms of the Creative Commons Attribution License, which permits unrestricted use and redistribution provided that the original author and source are credited.
In recent years, there has been an increase in bacterial resistance to antimicrobials found in both animals and humans, and in some countries, the use of antibiotics as growth promoters has been prohibited. Therefore, this article reviewed bacteriophages (viruses that infect bacteria) as a substitute for antibiotic-type growth promoters, since they can help control the main bacteria pathogens such as Salmonella and $E$. coli that affect birds, improve production parameters in broilers and laying hens, and are more efficient than antibiotic-type growth promoters.

Keywords: bacteriophages, promoter's growth, antibiotics, poultry.

\section{Resumen}

En los últimos años, la resistencia bacteriana a los antimicrobianos encontrada tanto en animales como en humanos y la prohibición del uso de antibióticos como promotores de crecimiento en algunos países son las nuevas variables a tener en cuenta. Por lo tanto, este artículo revisa los bacteriófagos (virus que infectan bacterias) como sustituto de promotores de crecimiento tipo antibiótico, ya que pueden ayudar a controlar los principales patógenos bacterianos como Salmonella y $E$. coli que afectan a las aves, mejoran los parámetros productivos en broilers y gallinas de postura y son más eficientes que los promotores de crecimiento tipo antibiótico.

Palabras Clave: bacteriófagos, promotores de crecimiento, antibióticos, avicultura.

\section{Introducción}

Las bacterias más importantes que aquejan a la producción avícola son Salmonella pullorum, Salmonella gallinarum y Escherichia. coli ya que producen mortalidad y cuantiosas pérdidas económicas en avicultura. Además, S. pullorum produce la enfermedad llamada pullorosis que afecta a las aves menores de 21 días de edad [1], la cual se transmite horizontal y verticalmente [2]. De igual forma, S. gallinarum produce la enfermedad llamada tifosis aviar y afecta a aves de cualquier edad y se transmite por vía oral y respiratoria [1,3]. Asimismo, E. coli produce la enfermedad llamada colibacilosis que afecta a las aves de cualquier edad y se transmite horizontalmente [4].

Por tal motivo, los antibióticos son usados para tratar y prevenir estas infecciones en animales. Sin embargo, en los últimos años ha aumentado el interés en los bacteriófagos 
o fagos, puesto que la resistencia bacteriana a los antimicrobianos encontrada tanto en animales como en humanos, la importancia de las aguas residuales de los centros de producción en la transferencia de dichos genes de resistencia [5-11] y la prohibición del uso de antibióticos como promotores de crecimiento en algunos países [12] son las nuevas variables a tener en cuenta.

En el presente trabajo se revisan los bacteriófagos como promotores de crecimiento y alternativa de tratamiento de enfermedades bacterianas en la industria avícola. Además, se revisan sus repercusiones sobre parámetros productivos y comparaciones con los promotores de crecimiento tipo antibiótico.

\section{Resultados y Discusión}

\subsection{Bacteriófagos}

Los bacteriófagos o fagos son los depredadores naturales de las bacterias, estos virus actúan como parásitos intracelulares de las mismas y tienen alta especificidad, por lo cual no afectan a los microorganismos benéficos [13]. Además, estos virus se encuentran en grandes cantidades en la naturaleza [14].

Los fagos tienen distintos ciclos de infección dentro del hospedero bacteriano: infección lítica, lisogénica, pseudo- lisogénica y crónica [15]. Según el ciclo de infección se pueden clasificar en fagos virulentos o líticos y fagos lisogénicos o templados. Los fagos líticos no permiten la multiplicación bacteriana, no obstante, los templados sí la permiten cuando la población de estas es baja. De hecho, los fagos templados juegan un papel importante al transmitir genes de resistencia antimicrobiana [16, 17]. Los estudios actuales de la fago-terapia se orientan al uso de fagos líticos, pertenecientes a los Caudovirales que comprenden a las familias Myoviridae, Siphoviridae y Podoviridae [18].

La infección de los fagos líticos inicia con el reconocimiento de receptores específicos en la membrana bacteriana y la consecuente adsorción del virus, luego, el fago introduce su material genético (ADN o ARN) en la bacteria y posteriormente se replica dentro de ella. Finalmente, liberan holinas y endolisinas para formar poros en la membrana, causando despolarización que produce lisis bacteriana y con ello liberación de nuevos fagos [19].

\subsection{Bacteriófagos usados contra bacterias que atacan a las aves}

Los fagos fueron obtenidos tanto de aguas residuales, heces y tejidos (Tabla 1), los cuales fueron desafiados con algunas de las principales bacterias patógenas que aquejan a la avicultura como las causantes de colibacilosis, tifosis y pullorosis aviar demostrando ser eficaces en reducir la mortalidad de las aves y la población de las bacterias patógenas; la mayor dosis empleada fue de $6,8 \times 10^{10}$ UFP/animal y se suministraron en medio sólido y líquido (Tabla 1). 
La vía oral es la más práctica en crianza comercial, ya que permite realizar tratamientos en grandes cantidades de aves con menos tiempo y recursos, mediante el agua o alimento (Tabla 1). Se ha demostrado que los fagos agregados tanto en el agua como en el alimento llegan a los distintos órganos internos afectados por las bacterias objetivo $[20,21]$. Además, según los estudios realizados, los efectos de la fago-terapia depende de la concentración y cantidad de dosis y la duración del tratamiento. La terapia con fagos mostró reducción de mortalidad en aves desafiadas con dosis letales de bacterias patógenas (Tabla 1).

\subsection{Fagos protegidos}

Según los trabajos realizados, el pH = 7 es el óptimo para estos virus, observándose reducción de títulos de fagos a medida que disminuye el $\mathrm{pH}$ y no resisten a medios muy

ácidos con $\mathrm{pH}<3$. Teniendo en cuenta que el $\mathrm{pH}$ gástrico de los pollos es aproximadamente 2,8 [25], es natural que muchos se pierdan en ese tramo del tracto digestivo y es necesario protegerlos $[22,23,25]$. Además, se observó disminución de títulos de fagos a temperatura de $70^{\circ} \mathrm{C}$ durante 40 min o más y que no resisten temperaturas mayores o iguales a $80^{\circ} \mathrm{C}$ [23], por lo que el proceso de peletizado o extrusión puede disminuir los títulos de fagos y es necesario protegerlos [23, 25]. Se probó la encapsulación para proteger los fagos evidenciando mejores resultados en la lisis de bacterias patógenas, esto debido a una menor pérdida de títulos de fagos al transitar por el sistema gastrointestinal que tiene cambios de $\mathrm{pH}$ y temperatura; observándose mejores resultados al disminuir las bacterias patógenas (Tabla 2) y de igual modo, se observó mejores resultados en cocteles que en fagos individuales (Tabla 2), aunque dichos estudios evaluaron a nivel de género y no de especie bacteriana. Por lo tanto, las estrategias para disminuir la pérdida de títulos de fagos de los cocteles mixtos de fagos líticos pueden ser: usar mayor dosis, seleccionar fagos resistentes o protegerlos.

\subsection{Fago-resistencia}

Dado que las bacterias y bacteriófagos co-evolucionaron desde la existencia de ambos, es lógico pensar que las presas (bacterias) han desarrollado estrategias para eludir a sus depredadores (fagos) y estos han desarrollado formas de superar dichas estrategias. De hecho, existen reportes sobre la fago-resistencia bacteriana [25-29] y se han estudiado los diversos mecanismos como: Pérdida de fago-receptores, modificación de fagoreceptores, sistema CRISPR-Cas y producción de matriz de polisacáridos [30].

La modificación y pérdida de fago receptores sirven para evitar la adhesión del fago a la superficie bacteria, pero esto reduce la multiplicación bacteriana y los fagos pueden cambiar sus fibras de cola para encontrar los receptores recién alterados [31]. En cuanto a la producción de polisacáridos, estos evitan la adhesión de los fagos, sin embargo, los fagos pueden producir despolimerasas para degradarlos [32]. Finalmente, el sistema CRISPR-Cas forma parte del sistema inmune adaptativo de las bacterias y lo utilizan para 


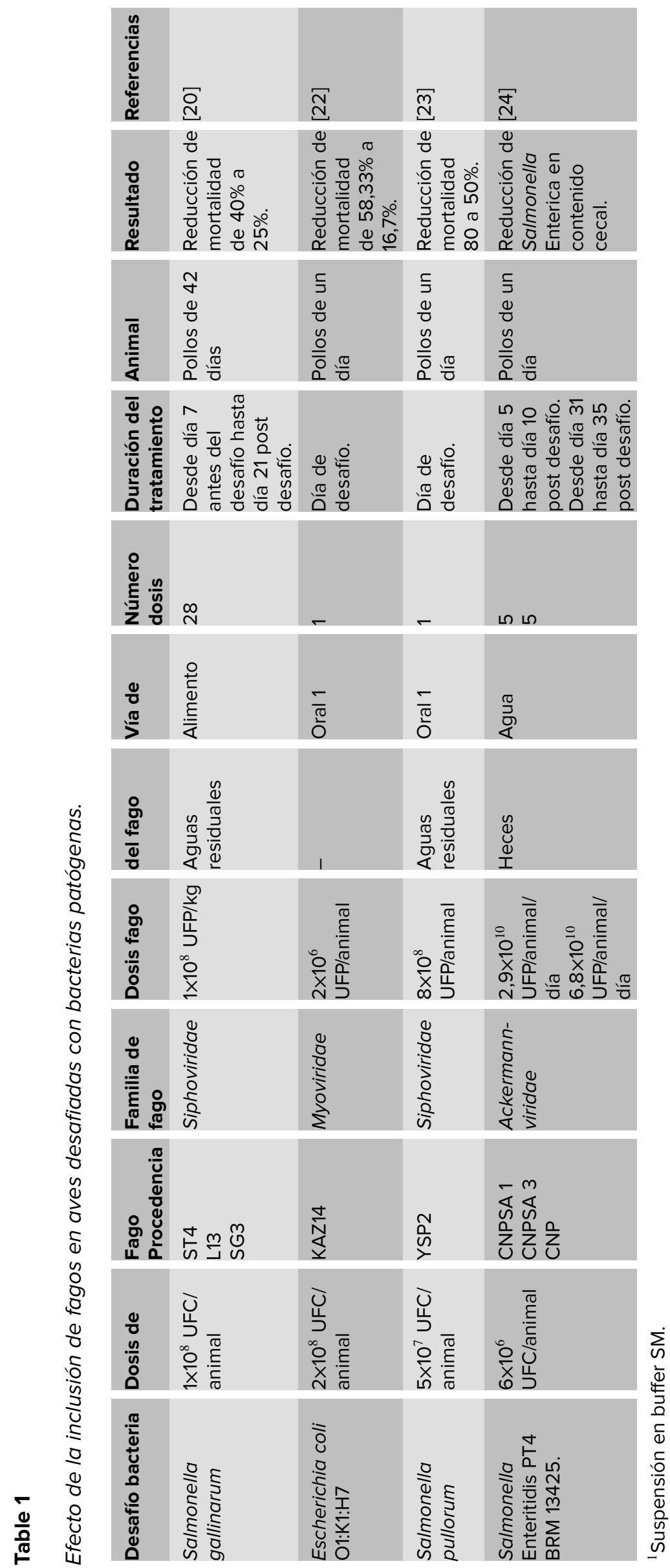




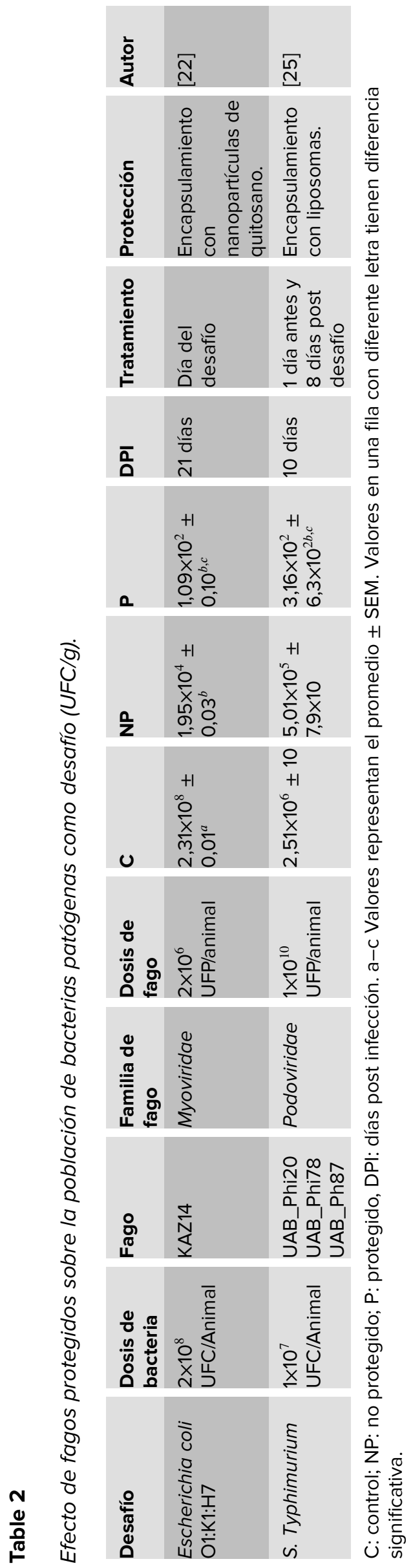


degradar el material genético del fago, no obstante, algunos fagos pueden proteger su material genético con una cubierta proteica [33]. Por otro lado, para combatir la fago-resistencia contamos con cocteles de fagos y quorum quenching [27, 34, 35].

\subsection{Empleo de cóctel de fagos en aves}

La mejor manera para emplear fagos en producción avícola comercial es mediante cocteles [36-43], ya que es difícil determinar todas las cepas bacterianas presentes en un centro de producción avícola y la presencia de bacterias fago-resistentes. Se han estudiado fagos individuales, cocteles simples y mixtos. La diferencia entre fagos individuales y cocteles es la cantidad de fagos contra un mismo género bacteriano, donde a partir de dos fagos se considera como coctel, sin importar a que familia de fago pertenecen [27]. La diferencia entre cocteles simples y cocteles mixtos radica en la variedad de fagos contra géneros bacterianos, donde se considera como coctel mixto a partir de dos géneros bacterianos [38,44]. Si bien es cierto que los fagos tienen un espectro limitado, los cocteles mixtos son una estrategia para ampliar dicho espectro.

Los estudios realizados iniciaron con dosis bajas y fueron aumentando gradualmente, incluso, incrementaron los géneros y cepas bacterianas objetivo, formando cocteles y demostrando resultados superiores a los fagos individuales. Además, los estudios parecen indicar que los cocteles mixtos son más eficientes que los cocteles simples al controlar la población de bacterias potencialmente patógenas que forman parte de la microbiota intestinal, aunque tengan menor dosis de fagos (Tabla 3).

Sin embargo, aún faltan más estudios que evalúen el recuento bacteriano post tratamiento de la cepa bacteria objetivo, ya que la mayoría de trabajos evalúan solamente los géneros bacterianos, asimismo, evaluar los efectos sobre microbiota intestinal y en menor medida la excreción, que se ha estudiado para controlar la transmisión horizontal. Del mismo modo, los fagos han demostrado sinergismo al emplearse junto a los probióticos y ser más efectivos que estos al reducir las bacterias patógenas $[13,38,40]$. Por tal motivo, se debería comparar con otras alternativas como prebióticos, aceites esenciales y ácidos orgánicos como se realizaron en otras especies animales $[13,40]$. Adicionalmente, se debería realizar estudios sobre el efecto de cocteles mixtos de fagos sobre el tamaño de vellosidades intestinales y profundidad de criptas en diferentes tramos intestinales.

\subsection{Efecto de los fagos sobre los parámetros productivos}

Los cocteles de fagos han mostrado efectos positivos sobre los parámetros productivos en pollos de engorde y gallinas de postura comercial. Según los estudios realizados, los cocteles mixtos tienen mejores resultados sobre la conversión alimenticia que los cocteles simples, existiendo diferencia estadística, aunque la dosis de cocteles simples sea mayor. Aunque, en algunos trabajos no se evidenció diferencia estadística en la conversión alimenticia al final del experimento, sí se logró evidenciar diferencia estadística en las primeras semanas de tratamiento [36]. 


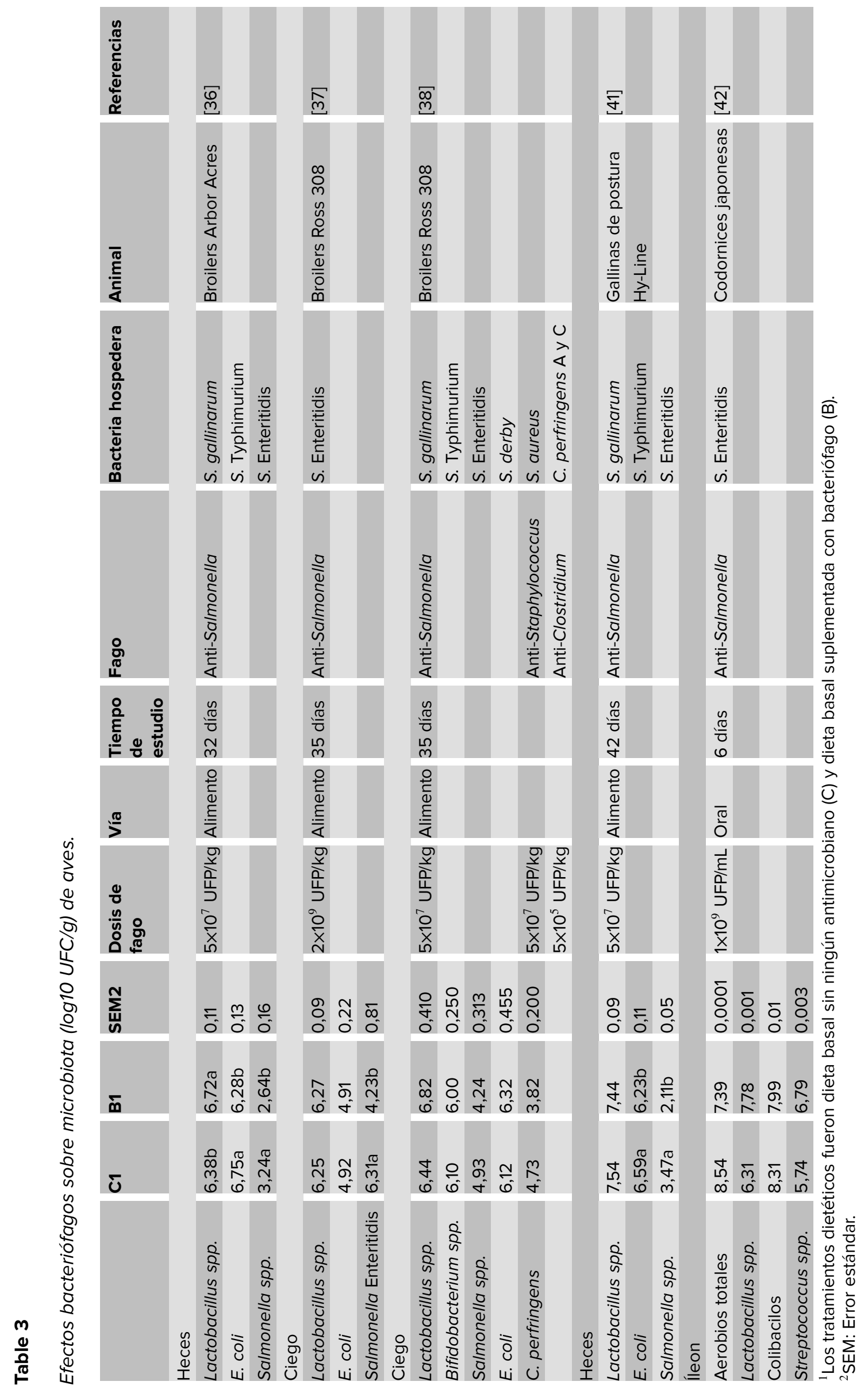


Además, los bacteriófagos aumentaron la producción y peso de huevos en las primeras semanas de producción de gallinas de postura comercial mostrando diferencia estadística (Tabla 4). Según lo expuesto en las subsecciones anteriores, se puede decir que fagos influyen indirectamente sobre los parámetros productivos al reducir las bacterias potencialmente patógenas y favorecen la multiplicación de las bacterias benéficas, lo que resulta en un mejor aprovechamiento de los nutrientes y que estos efectos pueden potenciar al usar fagos protegidos y mayores dosis.

\subsection{Comparación entre fagos y promotores de crecimiento tipo antibióticos}

Los trabajos realizados en aves demostraron que los bacteriófagos son más eficaces que los antibióticos al disminuir sólo las bacterias patógenas [36, 38], no obstante, se observó mejores resultados con cocteles mixtos de fagos (Tabla 5). Además, los fagos no sólo reducen la población de bacterias patógenas objetivo, sino que favorecen la multiplicación de las benéficas e indirectamente disminuyen las poblaciones de otras bacterias potencialmente patógenas (Tabla 5). Adicionalmente, los fagos son una buena alternativa contra bacterias resistentes a los antibióticos ya que los fagos utilizan mecanismos distintos a estos fármacos, sin embargo, falta realizar más estudios con mayores dosis de cocteles de fagos como los que utilizan actualmente $[23,25,45]$ y emplear fagos protegidos.

Una ventaja de los bacteriófagos frente a los antibióticos es que las bacterias resistentes a los antibióticos no pierden su capacidad de generar daño (virulencia), mientras que las bacterias resistentes a los fagos pueden ser menos patógenas. Dado que, los receptores de la superficie celular de las bacterias patógenas actúan como factores de virulencia, por lo que, al modificarlos para desarrollar fago-resistencia reduce su virulencia $[46,47]$. Sin embargo, la desventaja frente a los antibióticos sigue siendo el menor espectro de acción, por lo cual se propone el uso de cocteles mixtos de fagos líticos para aumentarlo. Los fagos pueden ser utilizados como promotores de crecimiento en los momentos críticos como el despique, vacunación (siempre que no se trate de vacunación contra bacterias) y traslado que afectan el consumo de alimento; y con ello evitar el aumento de bacterias potencialmente patógenas, que afectan negativamente los parámetros productivos.

\section{Conclusiones}

Los bacteriófagos líticos son una excelente alternativa frente al uso de antibióticos como promotores de crecimiento, ya que no afectan negativamente a las aves, ni a los microorganismos benéficos.

Se recomienda realizar más investigaciones sobre el empleo de fagos junto a otros promotores de crecimiento. 


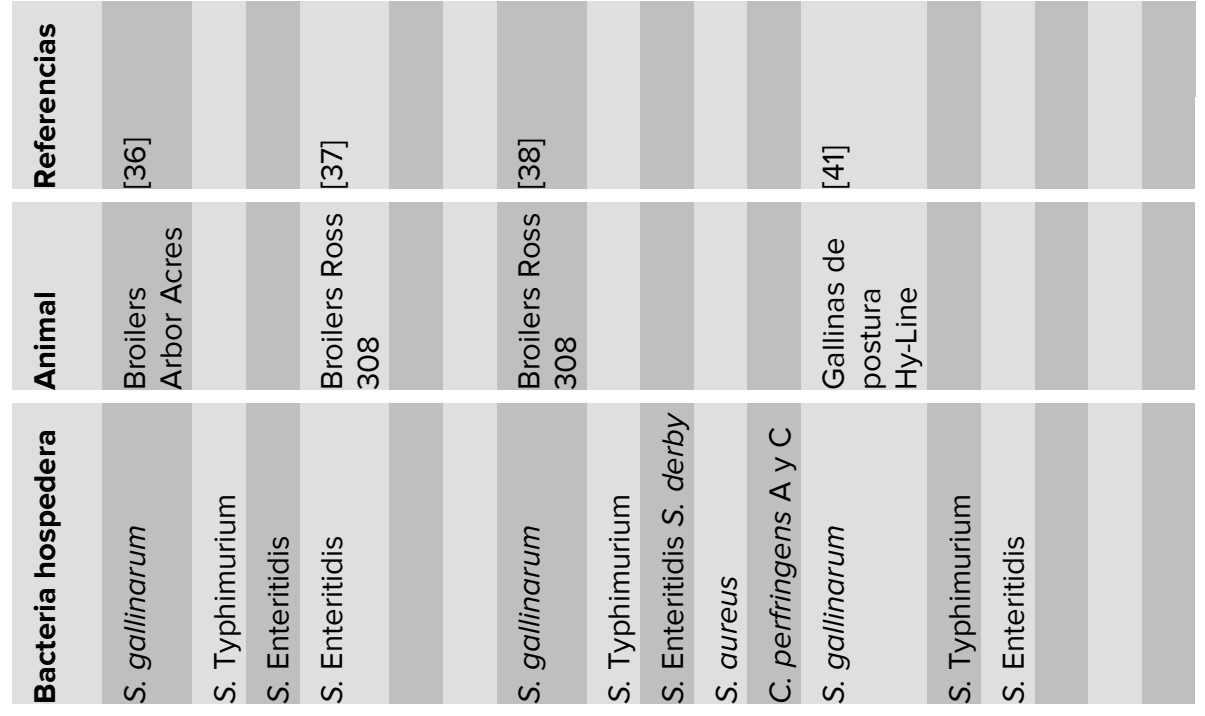

व
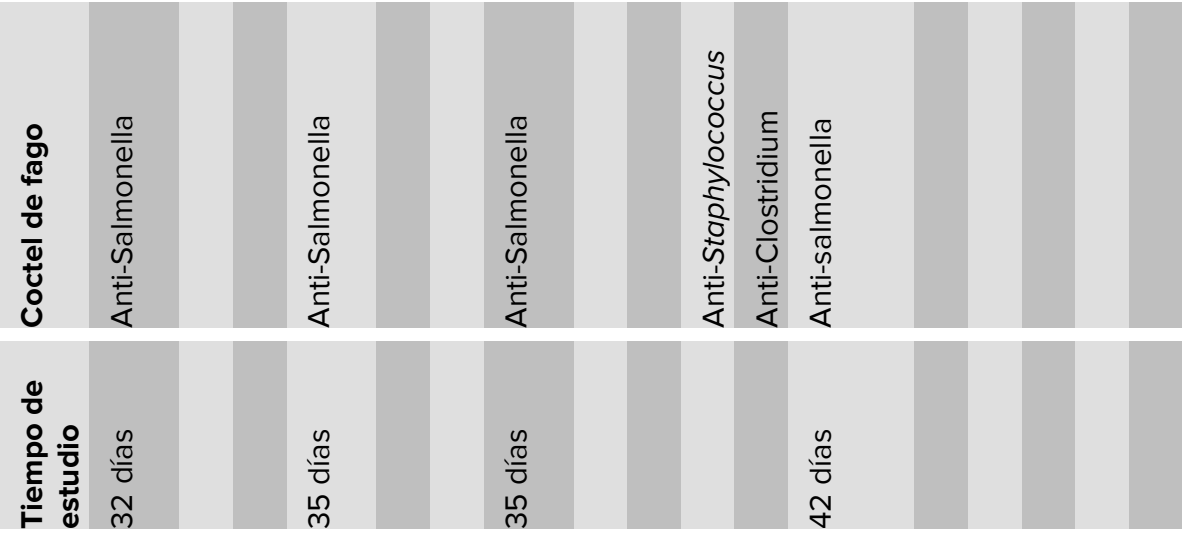

年,

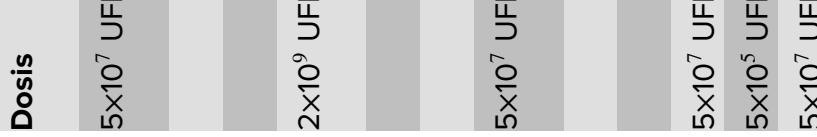
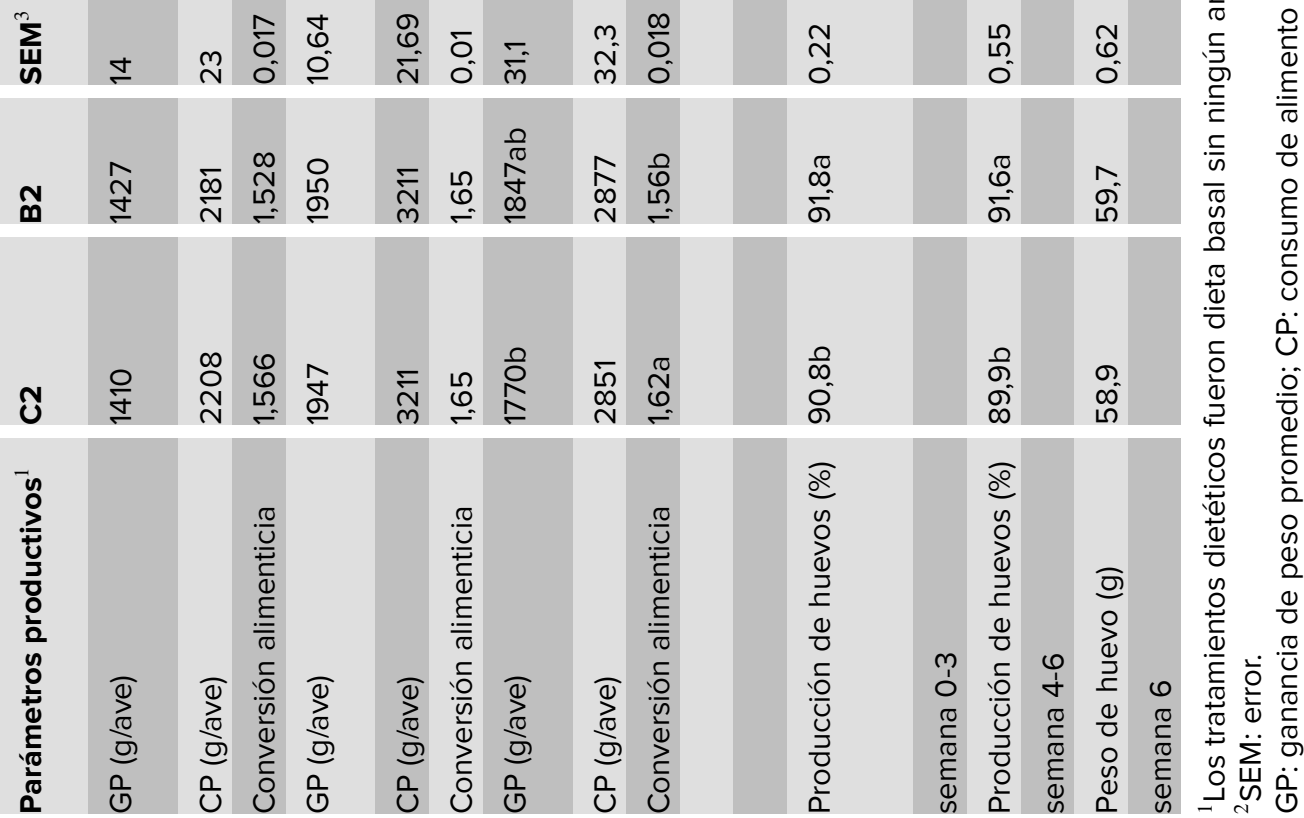


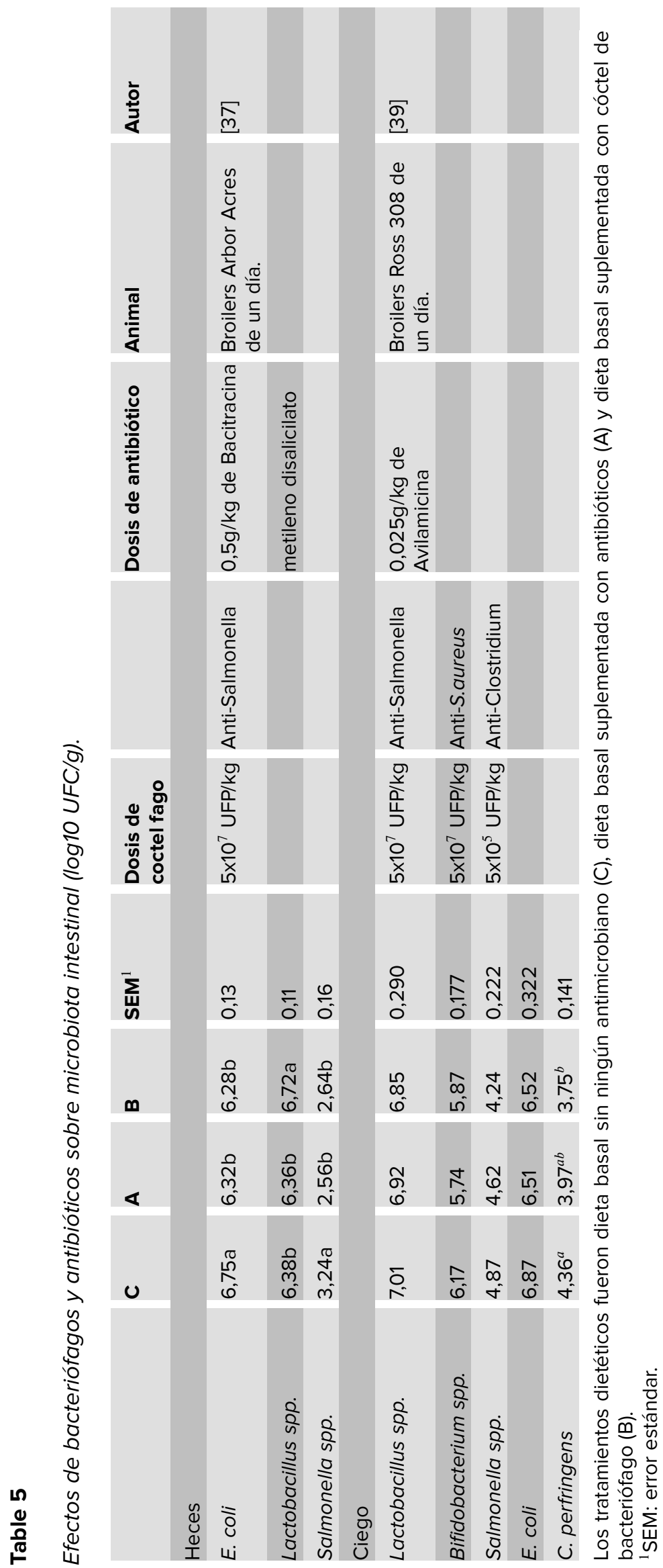


La protección de fagos ha demostrado ser una excelente herramienta para potenciar el efecto de los mismos, ya que reduce la pérdida de títulos de fagos al transitar en el tracto gastrointestinal.

Los cocteles mixtos de fagos líticos son excelentes sustitutos potenciales de antibióticos como promotores de crecimiento y tratamiento de enfermedades bacterianas que afectan a las aves.

Los cocteles mixtos de fagos líticos tienen mayor espectro que los cocteles simples y son una alternativa para combatir la fago-resistencia en avicultura.

El uso de cocteles mixtos tiene mejores resultados que los cocteles simples sobre los parámetros productivos y el control de bacterias patógenas.

\section{Agradecimientos}

Los autores agradecen infinitamente a la Universidad Privada Antenor Orrego de Trujillo.

\section{Conflictos de Intereses}

La investigación presente no tiene conflictos de intereses.

\section{References}

[1] Barrow P, Neto O. Pullorum disease and fowl typhoid - New thoughts on old diseases: A review. Avian Pathol. 2011;40(1):1-13

[2] Berchieri A, Murphy C, Marston K, Barrow P. Observations on the persistence and vertical transmission of Salmonella enterica serovars Pullorum and Gallinarum in chickens: Effect of bacterial and host genetic background. Avian Pathol. 2001;30(3):221-231.

[3] Basnet H, Kwon H, Cho S, Kim S, Yoo H, Park Y. Reproduction of fowl typhoid by respiratory challenge with Salmonella gallinarum. Avian Dis. 2008;52(1):156-159.

[4] Kabir S. Avian colibacillosis and salmonellosis: a closer look at epidemiology, pathogenesis, diagnosis, control and public health concerns. Int J Environ Res Public Health. 2010;7(1):89-114.

[5] Furtula V, Farrell E, Diarrassouba F, Rempel H, Pritchard J, Diarra M. Veterinary pharmaceuticals and antibiotic resistance of Escherichia coli isolates in poultry litter from commercial farms and controlled feeding trials. Poult Sci. 2010;89(1):180-188.

[6] Forgetta V, Rempel H, Malouin F, Vaillancourt Jr R, Topp E, Dewar K. Pathogenic and multidrug- resistant Escherichia fergusonii from broiler chicken. Poult Sci. 2012;91(2): 512-525.

[7] Manzetti S, Ghisi R. The environmental release and fate of antibiotics. Mar Pollut Bull. 2014;79(1):7-15.

[8] Marti E, Variatza E, Balcazar J. The role of aquatic ecosystems as reservoirs of antibiotic resistance. Trends Microbiol. 2014;22(1):36-41.

[9] Carvalho I, Santos L. Antibiotics in the aquatic environments: A review of the European scenario. Environ Int. 2016;94:736-757.

[10] Ngamwongsatit B, Tanomsridachchai W, Suthienkul O, Urairong S, Navasakuljinda W, Janvilisri T. Multidrug resistance in Clostridium perfringens isolated from diarrheal neonatal piglets in Thailand. Anaerobe. 2016;38:88-93.

[11] Zwe Y, Tang V, Aung K, Gutiérrez R, Ng L, Yuk H-G. Prevalence, sequence types, antibiotic resistance and, gyrA mutations of Salmonella isolated from retail fresh chicken meat in Singapore. Food Control. 2018;90:233-240.

[12] ESVAC. Sales of veterinary antimicrobial agents in 30 european countries in 2015. Trends from 2010 to 2015. 2017. Seventh Esvac Report. Ema/184855/2017.

[13] Gebru E, Lee J, Son J et al. Effect of probiotic-, bacteriophage-, or organic acid-supplemented feeds or fermented soybean meal on the growth performance, acute-phase response, and bacterial shedding 
of grower pigs challenged with Salmonella enterica serotype Typhimurium1. Journal of Animal Science. 2010;88(12):3880-3886.

[14] Breitbart M, Rohwer F. Here a virus, there a virus, everywhere the same virus? Trends Microbiol. 2005;13(6):278-284.

[15] Weinbauer M. Ecology of prokaryotic viruses. FEMS Microbiol Rev. 2004;28(2):127-181.

[16] Colomer-Lluch M, Jofre J, Muniesa M. Antibiotic resistance genes in the bacteriophage DNA fraction of environmental samples. PLoS One. 2011;6(3):e17549.

[17] Wipf J, Schwendener S, Perreten V. The novel macrolide-lincosamide-streptogramin B resistance gene erm (44) Is associated with a prophage in Staphylococcus xylosus. Antimicrob. Agents Chemother. 2014;58:6133-6138.

[18] Ackermann H. Bacteriophage taxonomy. Microbiol Aust. 2011;32(2): 90-94.

[19] Santos S, Costa A, Carvalho C, Nóbrega F, Azeredo J. Exploiting bacteriophage proteomes: The hidden biotechnological potential. trends in biotechnology. 2018;36(9):966-984.

[20] Hong S, Jeong J, Lee J, Kim S, Min W, Myung H. Therapeutic effects of bacteriophages against salmonella gallinarum infection in chickens. J. Microbiol. Biotechnol. 2013;23(10):1478-1483.

[21] Seo B.-J, Song E.-T, Lee K et al. Evaluation of the broad-spectrum lytic capability of bacteriophage cocktails against various Salmonella serovars and their effects on weaned pigs infected with Salmonella Typhimurium. Journal of Veterinary Medical Science. 2018;80(6): 851-860.

[22] Kaikabo A, Abdul Karim S, Abas F. Evaluation of the efficacy of chitosan nanoparticles loaded ФKAZ14 bacteriophage in the biological control of colibacillosis in chickens. Poultry Science. 2017;96(2):295302.

[23] Tie K, Yuan Y, Yan S et al. Isolation and identification of Salmonella pullorum bacteriophage YSP2 and its use as a therapy for chicken diarrhea. Virus Genes. 2018;54(3):446-456.

[24] Vaz C, Voss-Rech D, Alves L, Coldebella A, Brentano L, Trevisol I. Effect of time of therapy with wildtype lytic bacteriophages on the reduction of Salmonella Enteritidis in broiler chickens. Veterinary Microbiology. 2019;240:108527.

[25] Colom J, Cano-Sarabia M, Otero J, Cortés P, Maspoch D, Llagostera M. Liposome-encapsulated bacteriophages for enhanced oral phage therapy against Salmonella spp. Appl Environ Microbiol. 2015;81(14):4841-4849.

[26] Carvalho C, Gannon B, Halfhide D et al. The in vivo efficacy of two administration routes of a phage cocktail to reduce numbers of Campylobacter coli and Campylobacter jejuni in chickens. BMC Microbiology. 2010;10(1): 232-343.

[27] Fischer S, Kittler S, Klein G, Glünder G. 2013. Impact of a single phage and a phage cocktail application in broilers on reduction of campylobacter jejuni and development of resistance. PLoS ONE. 2013;8(10):78543.

[28] Sørensen M, Gencay Y, Birk T, Baldvinsson S, Jäckel C, Hammerl J. Primary isolation strain determines both phage type and receptors recognised by campylobacter jejuni bacteriophages. PLoS ONE 2015;10(1):0116287.

[29] Richards P, Connerton P, Connerton I. Phage biocontrol of campylobacter jejuni in chickens does not produce collateral effects on the gut microbiota. Front. Microbiol. 2019;10:476-486.

[30] Brockhurst M, Koskella B, Zhang Q.-G. Bacteriophages. Harper D, Abedon S, Burrowes B, McConville M. Springer International Publishing; 2017. Bacteria-Phage antagonistic coevolution and the implications for phage therapy. p. 1-21.

[31] Munsch-Alatossava P, Alatossava T. 2013. The extracellular phage-host interactions involved in the bacteriophage LL-H infection of Lactobacillus delbrueckii ssp. lactis ATCC 15808. Front Microbiol. 2013;4:408.

[32] Wang C, Li P, Niu W et al. Protective and therapeutic application of the depolymerase derived from a novel KN1 genotype of Klebsiella pneumoniae bacteriophage in mice. Research in Microbiology. 2019;170(3):156-164.

[33] Malone LM, Warring SL, Jackson SA et al. Un fago gigante que forma una estructura similar a un núcleo evade la orientación al ADN CRISPR-Cas, pero es vulnerable a la inmunidad basada en ARN de tipo III. Nat Microbiol. 2020;5(1): 48-55.

[34] Quiroz-Guzmán E, Peña-Rodriguez A, Vázquez-Juárez R., Barajas-Sandoval DR, Balcázar JL, MartínezDíaz SF. Bacteriophage cocktails as an environmentally-friendly approach to prevent Vibrio parahaemolyticus and Vibrio harveyi infections in brine shrimp (Artemia franciscana) production. Aquaculture. 2018;492:273-279.

[35] Mion S, Rémy B, Plener L, Brégeon F, Chabrière E, Daudé D. Quorum quenching lactonase strengthens bacteriophage and antibiotic arsenal against pseudomonas aeruginosa clinical isolates. Front. Microbiol. 2019;10:2049. 
[36] Wang J, Yan L, Lee J, Kim I. 2013. Evaluation of bacteriophage supplementation on growth performance, blood characteristics, relative organ weight, breast muscle characteristics and excreta microbial shedding in broilers. Asian-Australas J Anim Sci. 2013;26(4):573-578.

[37] Kim K, Lee G, Jang J, Kim J, Kim Y. Evaluation of Anti-SE Bacteriophage as Feed Additives to Prevent Salmonella Enteritidis (SE) in Broiler. Asian-Aust. J. Anim. Sci. 2013;26(3):386-393.

[38] Kim J, Kim J, Lee B et al. Effect of dietary supplementation of bacteriophage on growth performance and cecal bacterial populations in broiler chickens raised in different housing systems. Livestock Science. 2014;170:137-141.

[39] Lee SH, Hosseindoust AR, Kim JS et al. Bacteriophages as a promising anti-pathogenic option in creepfeed for suckling piglets: Targeted to control Clostridium spp. and coliforms faecal shedding. Livestock Science. 2016;191:161-164.

[40] Kim J, Hosseindoust A, Lee S et al. Bacteriophage cocktail and multi-strain probiotics in the feed for weanling pigs: effects on intestine morphology and targeted intestinal coliforms and Clostridium. Animal. 2017;11(01):45-53.

[41] Zhao P, Baek H, Kim I. Effects of bacteriophage supplementation on egg performance, egg quality, excreta microflora, and moisture content in laying hens. Asian-Australasian Journal of Animal Sciences. 2012;25(7):1015-1020.

[42] Ahmadi M, Torshizi M, Rahimi S, Dennehy J. 2016. Prophylactic bacteriophage administration more effective than post-infection administration in reducing salmonella enterica serovar enteritidis shedding in Quail. Frontiers in Microbiology. 2016;7:1253-1262.

[43] Clavijo V, Baquero D, Hernandez $S$ et al. Phage cocktail SalmoFREE ${ }^{\circledR}$ reduces Salmonella on a commercial broiler farm. Poultry Science. 2019;98(10):5054-5063.

[44] Schulz P, Robak S, Dastych J, Krzysztof Siwicki A. Influence of bacteriophages cocktail on European eel (Anguilla anguilla) immunity and survival after experimental challenge. Fish Shellfish Immun. 2018;84:28-37.

[45] Yan L, Hong S, Kim H. Effect of bacteriophage supplementation on the growth performance, nutrient digestibility, blood characteristics, and fecal microbial shedding in growing pigs. Asian-Aust. J. Anim. Sci. 2012;25(10):1451 - 1456.

[46] Skurnik M, Strauch E. Phage therapy: Facts and fiction. Int J Med Microbiol. 2006;296(1):5-14.

[47] Wagner PL, Waldor MK. Bacteriophage control of bacterial virulence. Infect Immun. 2002;70(8):39853993. 